\title{
TRANS-SELLAR TRANSSPHENOIDAL NASOPHARYNGEAL ENCEPHALOCELE
}

Parthasarathi $\mathrm{A}^{1}$, Kishor V.H²

\section{HOW TO CITE THIS ARTICLE:}

Parthasarathi A, Kishor V.H. "Trans-sellartranssphenoidal nasopharyngeal Encephalocele".Journal of Evolution of Medical and Dental Sciences 2013; Vol2, Issue 52, December 30; Page: 10092-10097

ABSTRACT: Trans-sellar trans-sphenoidalencephaloceles are rare and the trans-sellar variety is the least common. We present a 9-year-old male patient with trans-sellar trans-sphenoidal nasopharyngeal encephalocele which herniated into the nasopharynx through the congenital defect in the floor of sella. Patient presented with complains of nasal obstruction, nystagmus\& visual disturbance in left eye. A trans-sellar trans-sphenoidal nasopharyngeal encephalocele was found on computed tomography (CT) and magnetic resonance imaging (MRI).We discuss our clinical findings and the results of preoperative computed tomography and magnetic resonance imaging along with review of this rare condition.

INTRODUCTION: Encephaloceles occur in approximately1 in 3000 to 5000 live births ${ }^{1,2,3}$. Basal meningoencephaloceles are rare anomalies, reportedly constituting $1 \%$ - 10\% of all encephaloceles and originate from a congenital opening in the midline region of the skull base, which permits meninges, neural tissue or both to herniated from the intracranial space $4,5,6,7$.

Basal encephaloceles occur with an estimated incidence of one in every 35, 000 live births ${ }^{1}$. Pollock classifies them as follows:(1) Sphenopharyngeal or trans-sphenoidal, when they protrude into the epipharynx and/or sphenoidalsinus; (2) spheno-orbital, when the protrusion is through the superior orbital fissure into the superior orbit producing unilateral exophthalmus; (3) sphenoethmoidal, when the cerebral mass herniates through the sphenoid and ethmoidal bones into the posterior nasal cavity; (4) transethmoidal, whenencephalocele extends into the anterior nasal cavity; and (5) sphenomaxillary, when the meningo-encephalocele passes through the superior orbital fissure into the orbit and through the inferior orbital fissure into the pterygopalatine fossa ${ }^{8,9}$. Transsphenoidalencephaloceles are rare and the transsellar variety is the least common variety.

Wediscuss our clinical findings and the results of preoperativecomputed tomography and magnetic resonance imaging of trans-sellartrans-sphenoidal nasopharyngeal encephalocele along with review of this rare condition.

CASE REPORT: A 9 year old patient with normal built for age presented with complaints of nasal obstruction with anterior nasal discharge, nystagmus, headacheand visual disturbances more in left eye since 1 year. Clinical examination showed large nasopharyngeal soft tissue mass lesion causing near total occlusion of nasopharynx. Thesite of origin of the mass was not able to make out.Visual examination showed horizontal nystagmus in both eyes with decreased vision on left side.He had no history of CSF rhinorrhea, meningitis/seizures. His physical exam was unremarkable and the patient was referred for further work-up.

Radiograph of skull showed defect in the floor of sella [Fig.1]. Axial non enhanced computer tomography (NECT) showed large cerebrospinal fluid (CSF) density cystic lesion extending from sella, sphenoid sinus into nasopharynx[Fig 2] Bony defect noted in thesellar floor with widening of sella [Fig.3].Rest of the brain was normal. Diagnosis of trans-sphenoidalencephalocele was made. 
Unenhanced \& contrast enhanced magnetic resonance imaging (MRI) of brain showed large CSF intensity lesion extending from base of the brain in middle cranial fossa into the nasopharynx through thesellaand sphenoid sinus [Fig 4 \& Fig 5]. Part of optic chiasma was seen protruding into the proximal part encephalocele along with sellar widening. Pituitary gland was seen displaced posteriorly against the bone[Fig.6]. Rest of the brain was normal. Diagnosis of Trans-sellar transsphenoidal nasopharyngeal encephalocele was made.

DISCUSSION: Encephalocele is a cystic congenital malformation in which the central nervous system (CNS) structures, in communication with CSF pathways herniate through the defect in the cranium ${ }^{10}$, 11,12.If it contains only meninges it is termed a meningocele, when it also contains brain tissue it is called a meningoencephalocele. The primary abnormality in the development of an encephalocele is a mesodermal defect resulting in a defect of the bone and dura associated with herniation of CSF pathways, brain tissue and meninges through the defect ${ }^{10}$. One of the earliest and most widely accepted theories of basal encephalocele formation is the "adhesive theory, " published in 1827 by Sir Geoffroy Saint-Hilaire (as cited by Smith et al ${ }^{13}$ ). This theory attributes the bone defect to a faulty separation of neuroectoderm from the surface ectoderm during neural tube formation, thereby preventing mesodermal tissue, which is to form bone,from interposing between the two germ layers ${ }^{14}$.The root cause is the failure of surface ectoderm to separate from neuroectoderm early in the embryonic development.

Another possibility, as hypothesized by Kaufman et al, is herniation of tissue into the sphenoid sinus as a result of enlargement of congenital sphenoid "pitholes"; it has been estimated that up to $10 \%$ of the normal population may possess an aerated middle fossa floor. The hypothesis is that these small dehiscences may enlarge as a result of CSF pressure changes that occur during straining, coughing or normal physiological variations in intracranial pressure, thus allowing herniation of brain matter into sinuses.

Encephaloceles are classified as anterior (frontal, sincipital and basal) and posterior (infratorcular and supratorcular). Posterior encephaloceles are most common (75\%) and basal ones most infrequent (1.5\%) 10. Encephaloceles occur more commonly in females than in males. Currently, most encephaloceles are diagnosed antenatally and present at birth. Postnatally, infants may present with CSF rhinorrhea and recurrent meningitis ${ }^{15}$. They are often associated with midline craniofacial dysraphism. Some, particularly sphenoidalencephaloceles are often clinically occult and usually become apparent at the end of the first decade of life ${ }^{16}$.

Basal encephaloceles are rare with an estimated prevalence of one in 35, 000births anomalies and are classified into five types assphenoethmoidal, transethmoidal, sphenoorbital, sphenomaxillaryandtranssphenoidal.(1)Sphenopharyngeal or trans-sphenoidal, when they protrude into the epipharynx and/or sphenoidsinus; (2) spheno-orbital, when the protrusion is through the superior orbital fissure into the superior orbit producing unilateral exophthalmus; (3) sphenoethmoidal, when the cerebral mass herniates through the sphenoid and ethmoidal bones into the posterior nasal cavity; (4) transethmoidal, when the encephalocele extends into the anterior nasal cavity; and (5) sphenomaxillary, when themeningo-encephalocele passes through the superior orbital fissure into the orbit and through theinferior orbital fissure into the pterygopalatine fossa ${ }^{8,9}$.

The transsphenoidal variant represents approximately $5 \%$ of basal lesions. It is divided into intrasphenoidal, extending into the sphenoid sinus, and true transsphenoidal, traversing the floor of 
the sinus and protruding into the nasal cavity or nasopharyn $\mathrm{x}^{17}$. Trans-sphenoidalencephaloceles are rarecongenital anomalies that may be immediately apparent in infants with multiple cranial midline defects ${ }^{18}$. Inadults they can be of a spontaneous, traumatic or congenital origin ${ }^{19}$. Associated findings in trans-sphenoidalencephaloceles include agenesis of the corpus callosum, CSF rhinorrhea, an epypharyngeal soft tissue mass, visual defect, an endocrinological disturbance, and various optic and midface abnormalities ${ }^{17}$, such as an abnormal development of the optic nerve, the so-called morning glory syndrome ${ }^{20}$.

The majority of trans-sphenoidalmeningoencephaloceles are diagnosed during the first year of life due to manifestations such as respiratory distress caused by epipharyngeal obstruction, feeding difficulties, cranial midline defects with cleft lip or cleft palate, hypertelorism, optic malformations with anophthalmia, retinal abnormalities, optic nerve hypoplasia, unexplained bouts of recurrent meningitis or endocrine abnormalities $9,21,22,23,24$. However, if there are no considerable difficulties and no distinctive facial anomalies during childhood, the diagnosis of the disease may be delayed up to adulthood, when distinctive symptoms such as rhinorrhea, visual defect or endocrine dysfunction occur.

It must be noted that not all cases fallinto the above categories; Leblanc et al. have reportedthree cases in which meningoencephaloceles were found in the pterygopalatine fossa protruding through adefect at the base of the greater sphenoid wing near theforamen rotundum and the pterygoid process without the involvement of the orbit. These encephaloceles were not readily noticeable on CT scans of the middle fossaand were difficult to diagnose.

Several imaging features aid in the preoperative characterization of intrasphenoidalencephaloceles and subsequent management. Advanced imaging studies are necessary to confirm the diagnosis of trans-sphenoidalencephalocele and to define any neural or vascular elements that may be included in the herniation. CT scan and MRI are the most useful modalities for diagnosing encephalocele. In the present case, CT scan including reconstruction shows bone defects in the skull base and a well-circumscribed CSF density mass lesion in the extracranial area communicating with the intracranial space. MRI with gadolinium enhancement evaluated the content of the encephalocele and eliminated other intracranial anomalies.MR angiography may be needed to evaluate intracranial vasculature before surgical repair is performed.

\section{REFERENCES:}

1. OkanKahyaoluHalitCavusolu, Ahmet Murat Musluman, RamazanAlper Kaya, AdemYilma, YukselSahin, BurhanDadas, YunusAydin: TranssellarTranssphenoidal Rhino-Oral Encephalocele: Turkish Neurosurgery 2007l: 17: 4, 264-268

2. David DJ, Proudman TW. Cephaloceles: classification, pathology, and management. World Journal of Surgery1989;13(4):349-57

3. Jabre A, Tabaddor R, Samaraweera R. Transsphenoidalmeningoencephalocele in adults.Surgical Neurology 2000;54(2):183-8.

4. Itakura T, Miyamoto K, Uematsu Y, Hayashi S, Komai N.Bilateral morning glory syndrome associated with sphenoid encephalocele. Journal of Neurosurgery 1992;77(6):949-51.

5. Koral K, Geffner ME, Curran JG. Trans-sphenoidal and sphenoetmoidalencephalocele: report of two cases and review of the literature. Australasian Radiology 2000;44(2):220-4

6. MahapatraAK.Anteriorencephaloceles. Indian Journal of Pediatrics 1997;64(5):699-704 
7. Nishikawa T, Ishida $\mathrm{H}$, Nibu K. A rare spontaneous temporal meningoencephalocele with dehiscence into the pterygoid fossa. AurisNasus Larynx 2004;31(4):429-31.

8. IliasKantas, M.D., GeorgiosTzindros, M.D., Anna Papadopoulou, M.D., and NikolaosMarangos, M.D:MidfacialDegloving: The Best Alternative for Treatment of TranssphenoidalMeningocele of the PterygopalatineFossaSkull Base. 2006 May; 16(2): 117-122.

9. Pollock J A, New ton T H, Hoyt W F. Transsphenoidal and transethmoidalencephaloceles. A review of clinical and roentgen features in 8 cases. Radiology. 1968;90:442-453.

10. AndrejaVidaèiæ, Martina Matovinoviæ, AndrejaMariæ, Davorka Herman, Jure Murgiæ, Hrvoje Ivan Peæina, VatroslavÈerina and Milan Vrkljan: Transsphenoidalencephalocele.case report: ActaClin Croat 2005; 44:373-378.

11. Kumagai K. Congenital anomalies of the central nervous system, from the pediatric surgery. No ToHattatsu 1991;23:177-82.

12. ABET, LudeckeDK, WadaA, MatsumotoK. Transsphenoidalcephalocelesinadults.SurgNeurol 2000;142:397-400.

13. Smith D, Murphy M, Hitchon P, Babin R, Abu-Yousef M. Transsphenoidalencephaloceles. SurgNeurol1983;20:471-480

14. Jerry Blustajn, Ire`neNetchine, Daniel Fre'dy, Pierre Bakouche, Jean Daniel Piekarski, and Jean Franc,oisMeder: Dysgenesis of the Internal Carotid Artery Associated with TranssphenoidalEncephalocele: A Neural Crest Syndrome?:AJNR: 20:1154-1157.

15. Gerhardt von HJ, Muhler G, Szdzuy D, Biedermann F.Therapy problem in sphenoethmoidalmeningoceles. ZentralblNeurochir 1979;40:86-94.

16. Winniger SJ, Donnenfeld AE. Syndromes identified in fetuses with prenatal diagnosis of cephaloceles. PrenatDiagn 1994;14:839-43.

17. Jabre A, Tabaddor R, Samaraweera R. Transsphenoidalmeningoencephalocele in adults. SurgNeurol 2000;54:183-8

18. Smith DE, Murph MJ, Hitchon PW, Babin RW, Abuyousef MM. Transsphenoidalencephaloceles. SurgNeurol 1983;20:471-80.

19. Yokota A, Matsukado, Fuwa I, Moroki K, Nagahiros. Anterior basal encephalocele of the neonatal and infantile period. Neurosurgery 1986;19:468-78.

20. Itakura T, Miyamoto K, Uematsu Y, Hayashi S, Komain. Bilateral morning glory syndrome associated with sphenoid encephalocele. Case report. J Neurosurg 1992;77:949-51.

21. Chen CS, David D, Hanieh A. Morning glory syndrome and basal encephalocele.ChildNervus System 2004;20(2):87-90.

22. Diebler C, Dulac O. Cephaloceles clinical and neuroradiological appearance. Associated cerebral malformation. Neuroradiology 1983;25(4):199-216.

23. Kenna MA. Transsphenoidalencephalocele. Annals of Otology Rhinology Laryngology 1985;94(5 Pt 1):520-22.

24. Kennedy EM, Gruber DP, Billmire DA, Crone KR. Transpalatal approach for the extra cranial surgical repair of transsphenoidalencephaloceles in chidren. Journal of Neurosurgery 1997;87(5):677-81.

\section{TRANS-SELLAR TRANSSPHENOIDAL ENCEPHALOCELES}




\section{CASE REPORT}

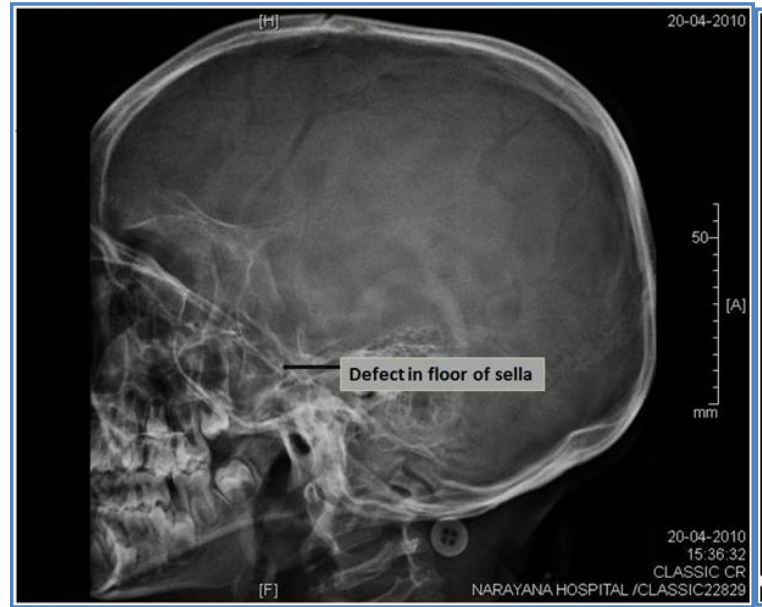

Fig.1: Lateral skull radiograph showing bony defect in the floor of the sella

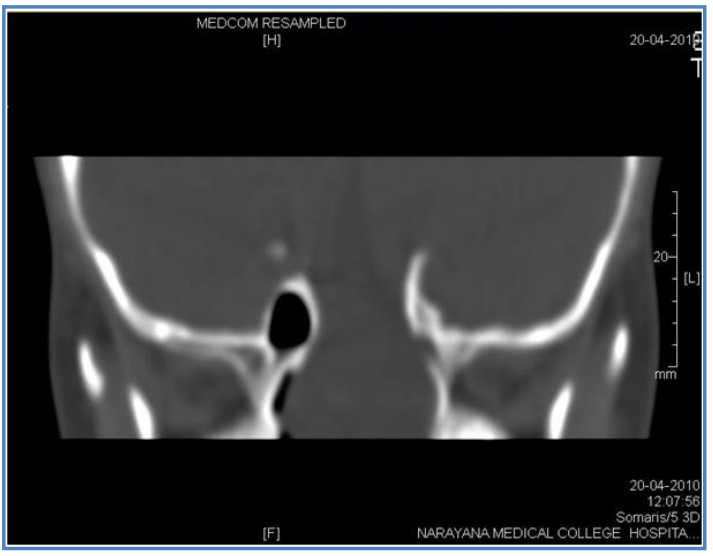

Fig. 3: Reconstructed CT showing defect in the floor of sella\& widening of sella

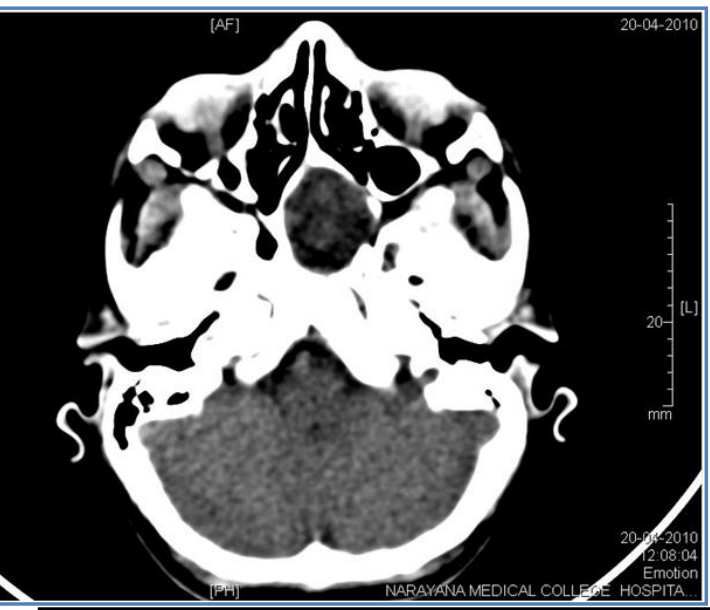

Fig. 2: Axial NECT showing CSF density cystic lesion in sphenoid sinus.

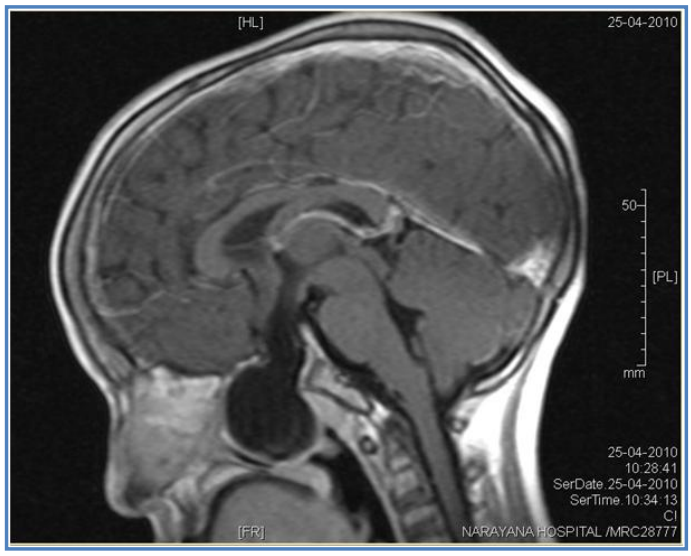

Fig. 4: T1W sagittal MR imaging of brain showing CSF intensity cystic lesion herniating from base of brain into nasopharynx- Encephalocele 


\section{CASE REPORT}

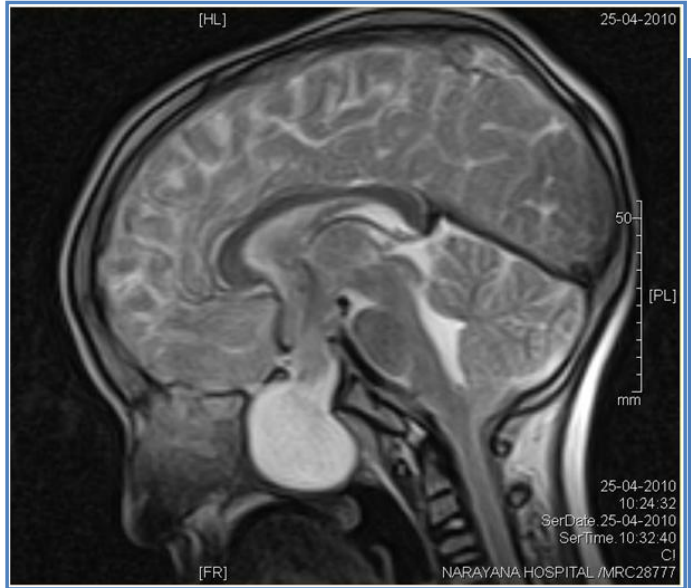

Fig. 5: T2W sagittal MR imaging of brain showing CSF intensity cystic lesion herniating from base of brain into nasopharynx-Encephalocele.

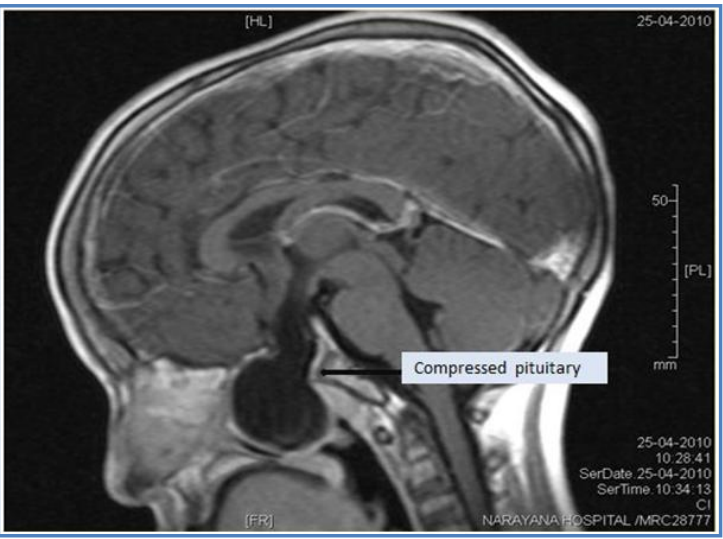

Fig. 6: CEMRI showing posteriorly displaced pituitary gland against bone

\section{AUTHORS:}

1. Parthasarathi A.

2. Kishor V.H.

\section{PARTICULARS OF CONTRIBUTORS}

1. Assistant Professor, Department of Radiodiagnosis, Narayana Medical College.

2. Professor\& HOD, Department of Radiodiagnosis, Narayana Medical College.

\section{NAME ADRRESS EMAIL ID OF THE} CORRESPONDING AUTHOR:

Dr. Kishor V.H., Professor \& HOD, Department of Radiology, Narayana Medical College, Nellore, Andhrapradesh. Email-kishorvh@gmail.com

Date of Submission: 11/11/2013. Date of Peer Review: 13/11/2013. Date of Acceptance: 05/12/2013. Date of Publishing: 24/12/2013 